\title{
Spontaneous expectoration of pulmonary metastases in a child with osteogenic sarcoma.
}

Hamza S Gorsi ${ }^{1}$; Mark LeGolvan ${ }^{2}$; Shamlal Mangray ${ }^{2}$; Bradley Denardo ${ }^{3}$; Jennifer Welch ${ }^{3}$

1: Department of Pediatrics, Division of Hematology Oncology, Wayne State University and Children's Hospital of Michigan, Detroit, MI.

2: Department of Pathology, Brown University and Rhode Island Hospital, Providence, RI

3: Department of Pediatrics, Division of Hematology Oncology, Brown University and Hasbro Children's Hospital, Providence, RI

Word Count (Main Text): 686

Number of files (Tables, Figures, Supplemental files): 3

Running Title: Spontaneous expectoration of tumor tissue

Keywords: Osteogenic Sarcoma, pulmonary metastases, endobronchial metastases, tumor expectoration

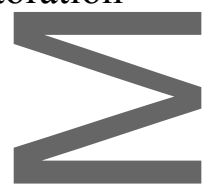

\section{Corresponding Author:}

Hamza Gorsi, MD, MPH

Children's Hospital of Michigan

3901 Beaubien Street, 3rd floor Carls Building

Detroit, MI, 48201

Phone: (313) 745-5515,

Fax: (313) 745-5237

Email:hgorsi@dmc.org,hgorsi@wayne.edu

This is the author manuscript accepted for publication and has undergone full peer review but has not been through the copyediting, typesetting, pagination and proofreading process, which may lead to differences between this version and the Version of Record. Please cite this article as doi: $10.1002 / \mathrm{pbc} .27611$.

This article is protected by copyright. All rights reserved. 


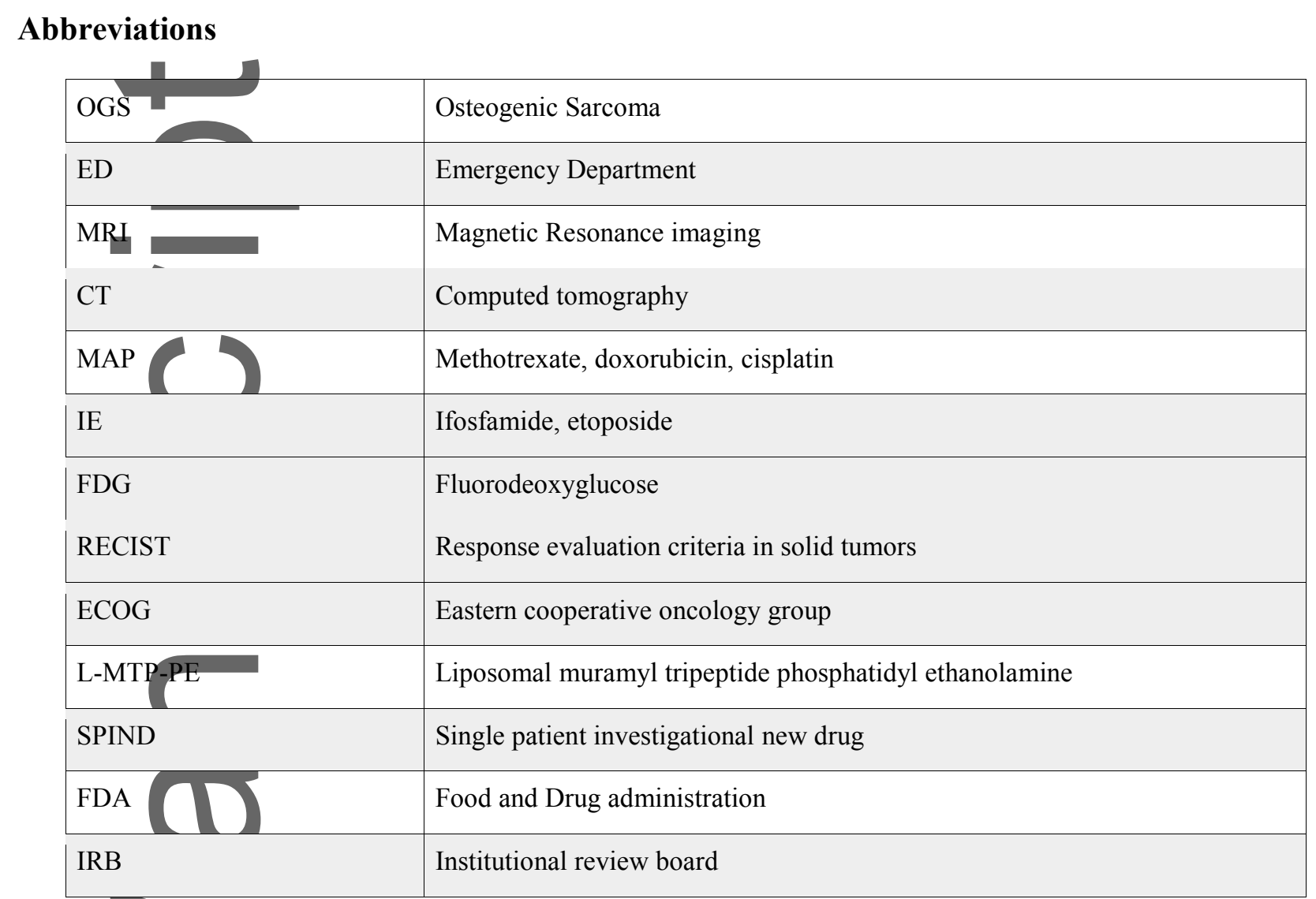
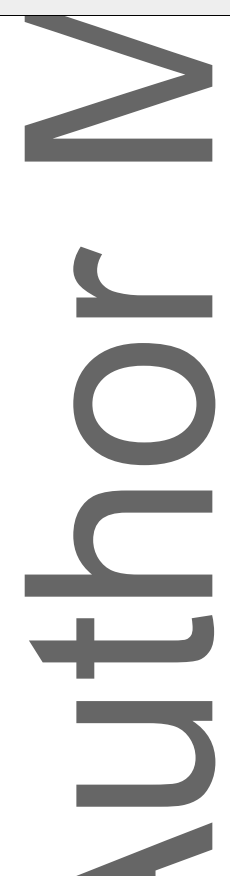

* This case report was previously presented as a poster at ASPHO 2018 on May 4, 2018 titled "A case report of spontaneous expectoration of pulmonary metastases in a child with osteogenic sarcoma"

This article is protected by copyright. All rights reserved. 


\section{Spontaneous expectoration of pulmonary metastases in a child with osteogenic sarcoma.}

To the editor: Pulmonary metastases from solid tumors can be parenchymal (peripheral) or endobronchial (central) (1). Endobronchial metastases are rare events, most frequently reported with breast, colorectal, kidney, stomach and prostate primaries (2). Occasionally, endobronchial metastases present with spontaneous expectoration of the metastatic tissue (1). Although there are few reports of spontaneous expectoration of the tumor tissue in adult literature, there is no such case reported in pediatric literature. We report a case of spontaneous expectoration of metastatic osteogenic sarcoma (OGS) tissue in a child.

A 9 year old female presented to the ED with pain and swelling of the right thigh after a fall in soccer field. X-ray of the leg showed a mass lesion on right lower femur, which was confirmed with a MRI leg. CT chest showed numerous bilateral pulmonary metastases, but bone scan was negative for bone metastases. Biopsy of the primary lesion was consistent with OGS. She was treated with methotrexate, doxorubicin, cisplatin (MAP) + zoledronic acid with addition of ifosfamide and etoposide (IE) following local control (rotationplasty). Her pulmonary lesions were not resectable due to high number of lesions and concern about the capacity of the residual lung tissue after resection of all the metastatic nodules. At completion of standard chemotherapy, her CT scan showed multiple residual pulmonary lesions with minimal FDG avidity in some of the pulmonary nodules, overall stable disease (RECIST 1.1), (ECOG performance score 1). Due to persistent pulmonary disease, she received maintenance sorafenib, everolimus and zoledronic acid. At 22 months from diagnosis, routine imaging showed new FDG-avid pulmonary lesions and increased FDG-avidity in older lesions, suggesting progressive disease. One week later, she presented to the hospital for respiratory distress secondary to complete collapse of right lung from a new metastatic lesion in the right main stem bronchus (Fig 1A, 1B, 1C), (ECOG performance score 3). She received targeted 
3000 cGy local radiation and her respiratory distress improved significantly. Post-radiation CT scan showed partial opening of right main stem bronchus (Fig 1D, 1E). Her chemotherapy was changed to gemcitabine and docetaxel. At 27 months from diagnosis, she expectorated a piece of necrotic tissue with degenerate cells and intermixed arborizing matrix (osteoid), consistent with post radiation necrotic changes in the tumor tissue (Fig 2). Post expectoration CT scan showed complete opening of the right main stem bronchus (Fig 1F, 1G, 1H), resolution of the intrabronchial metastasis and she returned to her baseline activity level (ECOG performance score 1). She continued to have other metastatic lesion in pulmonary parenchyma. At 30 months from diagnosis, she had disease progression when routine imaging documented development of new liver metastasis, which was treated with heat ablation. Systemic chemotherapy was changed to high dose methotrexate followed by liposomal muramyl tripeptide phosphatidyl ethanolamine (L-MTP-PE) as Single Patient Investigational New Drug (SPIND) after FDA and IRB approval (Fig 3).

At 34 months, patient developed back and abdominal pain and spontaneously expectorated pieces of tissue two times in an interval of two weeks. Pathologic evaluation of one of these specimens was again consistent with metastatic OGS making a total of three episodes of expectoration of tissue from metastatic OGS. Subsequently, L-MTP-PE was discontinued and she pursued alternative treatment options.

Expectoration of tumor tissue is a very rare event with only 30 reported cases in the literature (3), predominantly from metastatic cancers and only a few primary lung cancers. Most common metastatic cancers presenting as expectoration were renal cell carcinoma (4-7), colon cancer (8-9) and fibrosarcomas (10-11) while common lung primary cancers presenting with expectoration include squamous cell carcinoma, small cell lung cancer, bronchogenic carcinoids and primary sarcoma of lungs (12-16). Expectoration of the primary lung cancer occurs because of exfoliation of free tumor fragments in the airway. But endobronchial This article is protected by copyright. All rights reserved. 
metastases expectorate by releasing tissue into the airway after treatment related ulceration and necrosis (5).

Although endobronchial metastases are rare, they can cause airway obstruction and should be considered in the setting of acute worsening of the respiratory status. Local control with endoscopic surgery, radiation therapy, chemotherapy can relieve the airway obstruction and improve symptoms, and should be considered.

\section{Conflict of interest}

Authors of this case report have no conflict of interest to report.

\section{References}

1. Ghetie C, Davies M, Cornfield D, Suh N. Expectoration of a Lung Metastasis in a Patient with Colorectal Carcinoma. Clinical Colorectal Cancer 2008;7: 283-286. doi: 10.3816/CCC.2008.n.037.

2. Marchioni A, Lasagni A, Busca A, Cavazza A. Endobronchial metastasis: an epidemiologic and clinicopathologic study of 174 consecutive cases. Lung Cancer 2014;84:222-8. doi: 10.1016/j.lungcan.2014.03.005.

3. Ochi N, Yasugi M, Yamane H, Tabayashi T. Spontaneous Expectoration of Tumor Tissue in a Patient With Adenocarcinoma of the Lung. Respir Care 2012;57:1521-3. doi: 10.4187/respcare.01626.

4. Eissler M. Spontaneous regression of lung metastasis in renal cell carcinoma with expectoration of a part of the metastasis. [in German]. Med Klin (Munich) 1989;84:118-9.

5. Jariwalla AG, Seaton A, McCormack RJ, Gibbs A. Intrabronchial metastases from renal carcinoma with recurrent tumor expectoration. Thorax 1981;36:179-82.

This article is protected by copyright. All rights reserved. 
6. Seiler HH, Clagett OT, McDonald JR. Pulmonary resection for metastatic malignant lesions. J Thorac Surg 1950;19:655-79.

7. Daryanani S, Knausenberger HP, de Takats PG. Spontaneous pneumothorax associated with expectoration of a lump of metastatic renal cancer. Clin Oncol (R Coll Radiol) 1997;9:262-3.

8. Zias EA, Owen RP, Borczuk A, Reichel J. An unusual presentation of metastatic colon cancer to the lung. Chest 1998;113:244-6.

9. Gomez HL, Sanz RA, del Valle Rivero ML, et al. Spontaneous expectoration of a tumour fragment. An Med Interna 2005;22:501.

10. Clark MA, Hayes AJ, Thomas JM. Expectoration of endobronchial sarcoma metastasis. ANZ J Surg 2004;74:913-4.

11. Curry JJ, Fuchs JE. Expectoration of a fibrosarcoma; patient well 4 years later. J Thorac Surg 1950;19:135-7.

12. Kelly WF, Crawley EA, Vick DJ, Hurwitz KM. Spontaneous partial expectoration of an endobronchial carcinoid. Chest 1999;115:595-8.

13. Mital OP, Agarwala MC. Expectoration of a bronchogenic carcinoma. Br J Dis Chest 1968;62:52-3.

14. Kaira K, Shimizu Y, Sunaga N, Hisada T. Expectoration of bronchogenic tumour tissue. Intern Med J 2007;37:340-2.

15. Córdoba A, de Llano P, Arrechea MA, Beloqui R et al. Partial expectoration of a typical carcinoid: report of a case with diagnosis on sputum cytology. Acta Cytol 2006;50:581-3.

16. Watanabe R, Kamiyoshihara M, Kaira K, Motegi A et al. Spontaneous expectoration of primary pulmonary synovial sarcoma. J Thorac Oncol 2006;1:1025-6

This article is protected by copyright. All rights reserved. 


\section{Legends}

Figure1. A, B, C: Occlusion of right main stem bronchus with endobronchial metastatic lesion, presenting with respiratory distress D, E: Partial opening of the right main stem bronchus post radiation with resolved atelectasis $\mathrm{F}, \mathrm{G}, \mathrm{H}$ : Complete opening of the right main stem bronchus post expectoration of tumor tissue following radiation and chemotherapy.

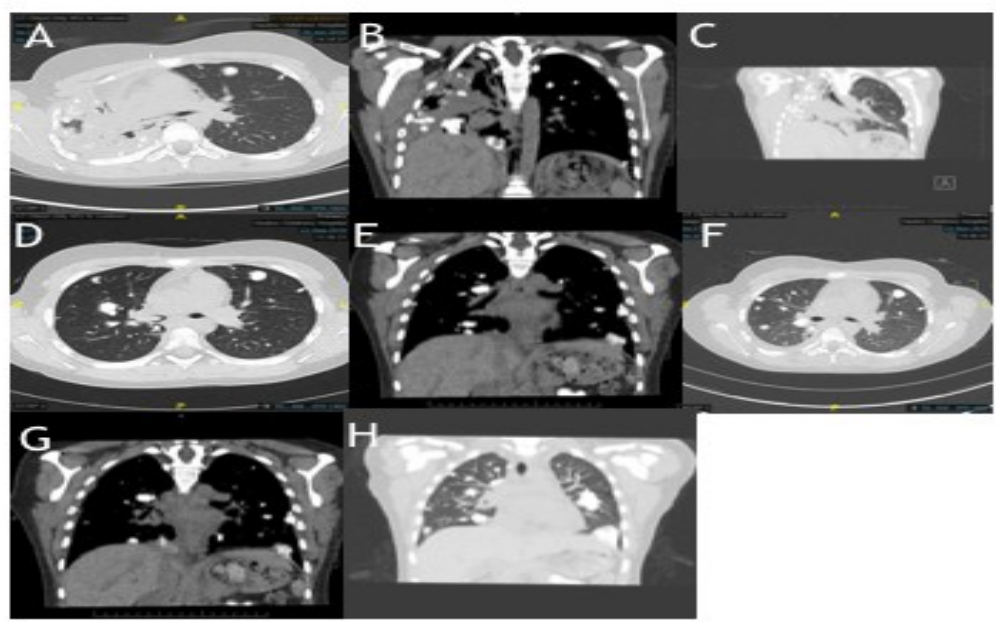

This article is protected by copyright. All rights reserved. 
Figure2. A: Low power image demonstrates a very vascular lesion with moderate cellularity and an attenuated epithelial lining at the top (arrow) B: A medium power image: a more cellular area with associated vascularity and the epithelial lining at the top. Islands of bone (arrows) are noted. C: This high power image: a focus with tightly packed tumor cells that are more atypical and associated with bone formation. Two mitotic figures (arrows) are noted.

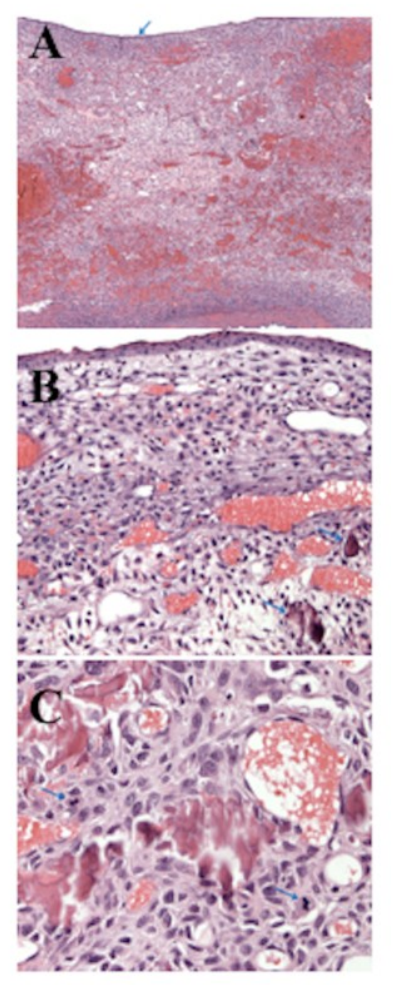

This article is protected by copyright. All rights reserved. 
Figure3: A summary of tumor directed treatments received by the patient with time line.

$\begin{array}{lll}\text { \&. Respiratory distress } & \text { Tumor expectoration of Surgery } \\ 4 & \text { Radiation } & \text { Thermal ablation }\end{array}$

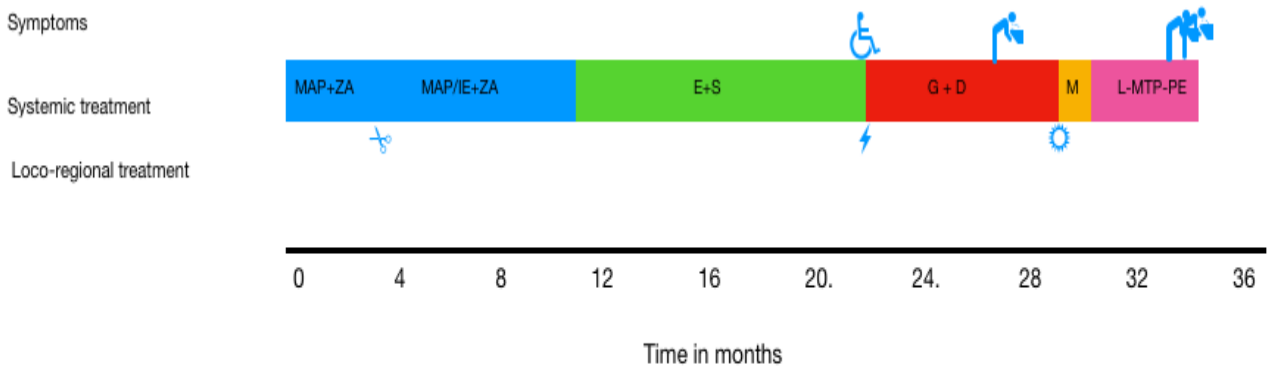

Abbreviations: MAP: methotrexate doxorubicin cisplatin; IE: ifosfamide etoposide; ZA: zoledronic acid; E: everolimus; S: sorafenib; G: gemcitabine; D: docetaxel; M: methotrexate; L-MTP-PE: liposomal muramyl tripeptide phosphatidyl ethanolamine;

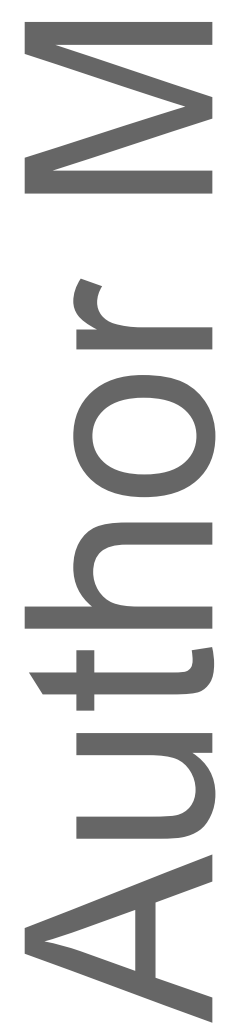

This article is protected by copyright. All rights reserved. 